\title{
The Diagnosis of Primitive Open Angle Glaucoma Beginning in Melanoderm Subject
}

\author{
Ndiaye JMM ${ }^{1 *}$, Ndoye RPA ${ }^{1}$, Kane $\mathrm{H}^{1}$, Nguer $\mathrm{M}^{1}$, Ba EA ${ }^{1}$, Sow $\mathrm{AS}^{1}$, Diagne \\ $\mathrm{JP}^{2}$, Diallo $\mathrm{M}^{2}$, Sow $\mathrm{S}^{2}$, Ka $\mathrm{AM}^{2}$, Ndiaye $\mathrm{PA}^{2}$ and Wane $\mathrm{AM}^{3}$ \\ ${ }^{1}$ Clinique Ophtalmologique, Hospital Aristide le Dantec Dakar, Senegal \\ ${ }^{2}$ Clinique Ophtalmologique, Centre Hospitalier Abass Ndao, Avenue Cheikh Anta Diop, Senegal \\ ${ }^{3}$ Service Ophtalmologie, hôpital d'enfants de Diamniadio, Senegal
}

*Corresponding author: Ndiaye JMM, Clinique ophtalmologique Hopital Aristide le Dantec

Dakar, 30 rue Pasteur, BP 3001 Dakar, Senegal, Tel: +221776175982; Email: josephmmndiaye@gmail.com

\section{Research Article}

Volume 5 Issue 1

Received Date: June 03, 2020

Published Date: June 24, 2020

DOI: $10.23880 /$ oajo-16000190

\section{Abstract}

Summary: OCT allow early detection of lesions related to primitive open angle glaucoma (POAG) particularly at the macular ganglion cell complex. This is the notion of glaucomatous macular disease.

Materials and Method: We conducted a multicenter descriptive prospective study over one year. Our study included patients melanoderm who had a visual acuity $\geq 3 / 10$ th, a C/D $>0.4$ and asymmetric, a visual field survey with $\mathrm{MD}<6$.

Results: We found 31 patients for suspicion of POAG. Nearly $90 \%$ of the eyes had a C / D between 0.4 and 0.6. At OCT, we found that the thickness of the ganglion cell complex was impaired in $16.4 \%$ of the eyes. The characteristic glaucomatous triptych consists of an attack of the macular nerve fiber layer (mNFL), associated with an attack of the GCIPL in the same sector. It constituted an infringement of POAG. It was found in $8.2 \%$ of eyes with doubtful involvement. The diagnosis of POAG was admitted in $24.6 \%$ of the eyes, 8 patients including one monophthalm.

Comments: The melanoderm would have the particularity of having a greater prevalence, precocity of appearance of the disease, a more aggressive evolution and a later diagnosis. To improve the prognosis of the disease, we looked for optical retinal tomography (OCT) retinal lesions of macular that allowed us an early diagnosis before any perimetric expression in adult subjects suspected of POAG.

Conclusion: The OCT allows a diagnosis of early stage GPAO including before-perimetric allowing, by better management, improved functional prognosis.

Keywords: Glaucoma; Macular Ganglion Cell Complex; Melanoderm; Senegal; Melanoderm

Abbreviations: PAOG: Primary Open-Angle Glaucoma; OCT: Optical Coherence Tomography; mNFL: macular Nerve Fiber Layer; IOP: Ocular Pressure; CCT: Central Corneal Thickness; MD: Mean Deviation; RNFL: Retinal Nerve Fiber Layer of Optic Nerve Head; GCIPL: Macular and Internal Plexiform Layer; GCC: Ganglionic Cell Complex.

\section{Introduction}

In melanodermes in developing countries, the diagnosis of primary open-angle glaucoma (PAOG) is rarely made at first. Moreover, it would be more aggressive in this field [1]. It is a condition that, in the absence of treatment, evolves 
inexorably towards blindness. It is therefore necessary to make the diagnosis early to initiate appropriate management in order to preserve visual function and quality of life. New exploration, such as Optical Coherence Tomography (OCT), offer us the opportunity to detect early glaucomatous lesions even before the characteristic alteration of the visual field. OCT can target early destruction of the retinal ganglion cell layer. It would be more pronounced at the macular level, where their thickness is greater [2,3]. The purpose of our study was to provide our experience of the use of OCT in the diagnosis of GPAO beginner in Senegalese melanoderm.

\section{Material and Methods}

We carried out a prospective and descriptive multicenter study at the ophthalmology services of the public health hospital Aristide Le Dantec, Abass Ndao and Diamniadio in Dakar (Senegal). It concerned patients received in consultation for suspicion of PAOG before the family history of PAOG, asymmetric cup disk (C/D) and at least one is greater than 0.3 or an INTRA ocular pressure (IOP) greater than $21 \mathrm{mmHg}$. They were not to have altered the transparency of the eye media and visual function. Their consent was required. We noted the risk factors in PAOG on a fact sheet, including the medical history of diabetes, low/ high blood pressure, family PAOG, and myopia. We performed a complete ophthalmological examination to detect visual acuity, IOP, at the Goldmann tonometer and C/D, central corneal pachymetry with Quantel ultrasound, visual field survey with an automated perimeter "Octopus 300", and the Topcon 3D Camera OCT 2000 (ver 8.00). Pachymetry was used to measure the central corneal thickness (CCT) and to determine the correction to be made to the IOP values. Hypertonia was retained when the ocular pressure was greater than $21 \mathrm{mmHg}$. The normal CCT was between 527 and $560 \mu \mathrm{m}$. The CCT less than $527 \mu \mathrm{m}$ were considered thin. The perimeter survey highlighted the type of deficit and gave the mean deviation (MD) with a normal of less than 6. We performed an OCT of the anterior segment to specify the opening of the AIC and then one of the posterior segments for a structural examination of the optic disc and macula. The $\mathrm{C} / \mathrm{D}$, retinal nerve fiber layer of optic nerve head (RNFL) and macular nerve fibre layer (mNFL), macular and internal plexiform layer (GCIPL) were noted on the surveys, and the thickness of the macular ganglionic cell complex (GCC). We appreciated the characteristic macular glaucomatous triptych corresponding to GCIPL and MNFL in the same area. We divided our population into three groups according to the thickness of the layer studied (Table 1). The diagnosis was confirmed in Group 1 patients and when the macular glaucomatous characteristic triptych, which was GCIPL mediated by mNFL layer deficiency in the same area [4], was in Group 2 patients. Data analysis was done with Epi info 5 Version 3.3.2 software.

\begin{tabular}{|c|c|c|c|}
\hline & Group 1 & Group 2 & Group 3 \\
\hline RNFL $(\mu \mathrm{m})$ & $\leq 90$ & $90-100$ & $\geq 100$ \\
\hline mNFL $(\mu \mathrm{m})$ & $\leq 27$ & $27-30$ & $\geq 30$ \\
\hline GCIPL $(\mu \mathrm{m})$ & $\leq 54$ & $54-60$ & $\geq 90$ \\
\hline GCC $(\mu \mathrm{m})$ & $\leq 87$ & $87-90$ & \\
\hline
\end{tabular}

Table 1: Distribution into groups according to the thickness of the layers of nerve fibers, ganglion cells and plexiform.

\section{Results}

Our sample consisted of 61 eyes from 31 patients. One of them was with one-eyed. The average age was $46 \pm 14.16$ years with extremes 19 and 69 years. Thirteen patients (41.9\%) were under 40 years of age. The sex ratio was 1.18. Risk factors were found in $83.87 \%$ of our patients. We counted $45.16 \%$ of patients with a medical history of high blood pressure (35.49\%), low blood pressure (3.22\%), and diabetes (6.45\%). Those with a family history of PAOG were $61.29 \%$. Other risk factors were found in ten patients (32.25\%). They were type of myopia $(25.80 \%)$, elevated IOP $(3.22 \%)$. The mean visual acuity after correction was $9.8 \pm 0.17$ with extremes $7 / 10$ th and $10 / 10$ th. The average corneal thickness was $518 \pm 27.29 \mu \mathrm{m}, 45.9 \%$ had a thin cornea. The mean ocular tone was $17.24 \pm 2.79 \mathrm{mmhg}$ and the mean corrected ocular tone was $19.02 \pm 2.89 \mathrm{mmhg}, 24.6 \%$ had hypertonia. All our patients had an iridocorneal angle open to gonioscopy with a stage 4 of Shaffer's classification. The same was true for the OCT. The mean C/D was $0.55 \pm 0.09$ with extremes of 0.4 and 0.7 . There were $86.9 \%$ of eyes with a C/D between 0.4 and 0.6 . The OCT had $81.97 \%$ of eyes with a C/D between 0.4 and 0.6 . At the automated perimetry, the average of the standard deviations (MD) was $1.70 \pm 1.4$ with extreme values of -1.6 to 4.4 . Thirty-four eyes or $55.7 \%$ did not show any visual field alteration. Of the remaining 27 eyes (44.3\%), minimal deficits were not systematic. At the OCT, the thickness of nerve fibres layer (RNFL) was in mean $100.93 \pm 11.53 \mu \mathrm{m}$. Seven eyes or $11.5 \%$ were in group 1 (Table 2). The thickness of the ganglionic and plexiform cell layers (GCIPL) was in mean $67.188 .43 \mu \mathrm{m}$ and $4.9 \%$ was Group 1 (Table 2). The ganglion cell complex (GCC) thickness was $95.92 \mu \mathrm{m}$, with $16.4 \%$ in Group 1 (Table 2). The lower quadrant was reached in $14.8 \%$ and the upper quadrant 


\section{Open Access Journal of Ophthalmology}

was impaired in $13.1 \%$. The search for glaucomatous characteristic triptych, in patients in group 2 , noted $8.2 \%$ of the eyes. The diagnosis of glaucoma was therefore established in $24.6 \%$ or 8 patients whose patient was monophtalmous.

\begin{tabular}{|c|c|c|c|}
\hline & Group 1 & Group 2 & Group 3 \\
\hline RNFL & $11,5 \%$ & $23 \%$ & $65,5 \%$ \\
\hline GCIPL & $4,9 \%$ & $13,1 \%$ & $82 \%$ \\
\hline GCC & $16,4 \%$ & $8,2 \%$ & $75,4 \%$ \\
\hline
\end{tabular}

Table 2: Distribution of patients in groups according to the severity of the damage according to the thickness of the layers of nerve fibers, ganglion cells and plexiform.

\section{Discussion}

The melanoderm subject would have the particularity of having a greater prevalence, precocity of the disease, a more aggressive evolution and a later diagnosis [1]. Melanoderm would also be a aggravating factor for the disease with a higher rate of blindness [5]. The prevalence of glaucoma with open angle would be tripled in melanoderm compared to Caucasians $[1,6]$. The family history of PAOG would be predisposed to the onset of the disease [6]. This risk of developing PAOG would be higher when one of the parents is reached [4]. The importance of risk factors for PAOG in our population motivated the detection of the disease in these patients received in consultation in our hospital. The melanoderm subjects would have a thinner cornea than the Caucasian subjects, in our sample nearly half of the patients had a thin cornea. It is therefore necessary to perform pachymetry in the melanoderm glaucomatous gland, in order to adjust the IOP for the diagnosis and monitoring of PAOG $[1,7]$.

In the PAOG, injury of the thickness of RNFL results in an arciform deficit in same side at the perimetry [8]. The impairment was proven for our patients in group 1 . However, the absence of significant injuries of the visual field of our patients, would be explained by a not very severe infringement of the thickness of the peripapillary optical fibers because the pathology would be at beginning. There is reportedly a relationship between nerve fibre involvement and macular lesions observed in PAOG. Indeed, any lesion of the optic nerve on the whole of its path would lead to a degeneration of ganglion cells that can be identified by the OCT analysis of the ganglion cell complex (GCC). In PAOG, OCT of macula would show early structural damage to the fovea, even before irreversible functional damage $[8,9]$. Nearly half of our patients with GCC had pRNFL involvement. These two parameters would be complementary, the study of peripapillary nerve fibers would be more sensitive for the detection of peripheral forms and central lesions are better detected by OCT of cellular complex ganglionnic.

Asymetry of macular nerve fibres (mNFL) can be a physiological anatomical variation. When this breach is associated with a GCIPL breach in the same area, it is the triptych characteristic of the PAOG [4]. Indeed, the peripapillary fibre optics would be prolonged by the involvement of ganglionic cells [10]. We looked for it in our patients in group 2 . It was found in $8.2 \%$ of cases. These eyes could be considered as having PAOG. Therefore, we established PAOG in $24.6 \%$ of the eyes or 8 patients. The rest of the patients in group 2, 4.9\% of the eyes, should benefit from rigorous and periodic monitoring, in search of early structural alterations. In them the doubt remained.

\section{Conclusion}

Thanks to the OCT, we were able to confirm the diagnosis in some patients, for whom the examination and automated perimetry had not allowed. Thus a mapping of the macular ganglionic complex and peripapillary nerve fibers should be standard for diagnosis and monitoring of suspected PAOG patients. It would allow for early and more appropriate management of glaucomatous melanodemas.

\section{References}

1. Denis P (2004) Le glaucome chez le mélanoderme. J Fr Ophtalmol 27(6): 708-712.

2. Baumrind LAK, Quigley HA, Pease ME, Kerrigan DF, Mitchell RS (2000) Number of ganglion cells in glaucoma eyes compared with threshold visual field tests in the same persons. Invest Ophthalmol Vis Sci 41(3): 741-748.

3. Quigley HA, Dunkelberg GR, Green WR (1989) Retinal ganglion cell atrophy correlated with automated perimetry in human eyes with glaucoma. Am J Ophthalmol 107(5): 453-464.

4. Zeitoun M (2010) Atteintes périmaculaires du glaucome des cellules ganglionnaires en tomographie en cohérence optique. J Fr Ophtalmol 33(10): 758-765.

5. Renard JP, Sellem E (2014) Le glaucome chronique à angle ouvert. Rapport annuel de la Société Française 
d'Ophtalmologie pp: 747.

6. Bron A, Chaine G, Villain M, Colin J, Nordmann JP (2008) Facteurs de risque du glaucome primitif à angle ouvert. J Fr Ophtalmol 31(4): 435-444.

7. (2003) European glaucoma society. Guide pour le glaucome DOGMA Savona.

8. Zahir F (2011) Glaucome primitif à angle ouvert à propos de 140 cas. These med Fes pp: 167.

9. Lefrancois A (2008) Mon expérience de l'OCT du segment postérieur pour le dépistage et suivi objectif du glaucome. J Fr Ophtalmol 31(6): 2S10-2S18.

10. Renard JP, Fenolland JR, El chabab H, Francoz M, Marill $\mathrm{AM}$, et al. (2013) Analyse du complexe cellulaire ganglionnaire maculaire en SD-OCT dans le glaucome. J Fr Ophtalmol 36(4): 299-309. 